\title{
ЛИТЕРАТУРОВЕДЕНИЕ
}

\section{СОЛИПСИЗМ В РОМАННОЙ ПОЭТИКЕ ВИКТОРА ПЕЛЕВИНА} SOLIPSISM IN THE POETICS OF VIKTOR PELEVIN'S NOVELS

\author{
MATEUSZ JAWORSKI
}

\begin{abstract}
The philosophical doctrine of solipsism plays an extremely significant role in Viktor Pelevin's works as a core idea which undergoes the process of formal modifications. In this paper this process is referred to as "reconfiguration". The article presents different representations of solipsism in Pelevin's novels. The analysis is preceded by a brief introduction to the philosophical roots of the doctrine.
\end{abstract}

Mateusz Jaworski, Uniwersytet im. A. Mickiewicza w Poznaniu, Poznań - Polska, matjaw@amu.edu.pl

В поисках доминирующего элемента поэтики романов Виктора Пелевина можно обнаружить несколько весомых мотивов, используемых русским писателем с интригующей последовательностью и частотой. Некоторые критики считают такое устойчивое присутствие повторяющихся идей недостатком стиля, творческой исчерпанностью или даже проявлением целеустремленной коммерческой жажды максимальной прибыли ${ }^{1}$. В нынешней работе, однако, ставится тезис о реконфигурационном характере произведений автора Священной книги оборотня, согласно которому повторение оказывается своеобразным усилителем семантического потенциала текста или, может быть, модусом закрепления его идейного ядра. Главным положением данной постановки вопроса является сосуществование двух пересекающихся текстовых слоев в пределах структуры интересующих нас романов: идеи, подвергающейся процессу реконфигурации, и формы, реконфигурирующей эту идею. Проза Пелевина в таком ракурсе похожа на констелляцию смыслов, вплетенную в сложную ткань различных форм. Следовательно,

${ }^{1}$ См., например, А. Н е м з е р, Как я упустил карьеру, [в:] электронный ресурс: http:// pelevin.nov.ru/stati/o-nemz/1.html (05.04.2016); М. С в е р д л о в, Хорошая защита плохой прозы, [в:] электронный ресурс: http://www.globalrus.ru/impressions/133635 (01.12.2015). 
любая идея обладает целой бесконечностью возможных вариантов художественной экспрессии, не лишаясь своей имманентной цельности.

Среди преобладающих реконфигурируемых мотивов в рамках текстов автора Смотрителя безусловной привилегированностью пользуется солипсистское восприятие действительности. На основе подробного анализа исследуемого нами материала (романной деятельности Пелевина с Омон $\mathrm{Pa}$ по Смотрителя) можно констатировать, что солипсизм, несомненно, оказывается отправной точкой или, может быть, идейным фоном для всех других существенных мотивов прозы Пелевина, включая влиятельность языка при восприятии реальности и историософию. В дальнейшей части наших размышлений постараемся охарактеризовать солипсистскую позицию с точки зрения философии, а также определить главные элементы пелевинского понимания этой доктрины и провести соответствующий контекстуальный анализ романов автора Синего фонаря.

Корни идеи солипсизма в европейской философии связаны с софистом Горгием, жившим в V и VI веках до нашей эры ${ }^{2}$. Греческий философ в своем трактате под заглавием $O$ не-сущем, или $O$ природе 3 предложил три утверждения, в будущем ставшие первым манифестом агностицизма и солипсизма: 1) ничего не существует, 2) даже если нечто существует, оно непознаваемо, 3) даже если нечто познаваемо, о нем невозможно сообщить другому человеку4. Горгий, согласно своему своеобразному способу рассуждения, проанализировал парадокс существования следующим образом - все объекты, являющиеся объектом мысли, не реальны, а все объекты, не являющиеся объектом мысли, реальны. Следовательно, не существует такой реальности, которая была бы объектом мысли, но если хотя бы один объект мысли реален, все такие объекты реальны ${ }^{5}$. С точки зрения творчества Пелевина особенно любопытным оказывается решение третьего положения, в котором Горгий на примере восприятия цветов утверждает, что знак не равнозначен означаемому - невозможно объяснить представление о цвете с помощью слов, так как ухо слышит звуки, а не цвета6. Конечно, не-

\footnotetext{
${ }^{2}$ Ср. М. Я в о р с к и, Нарративныйпринцип солипсизма В творчестве В. Пелевина как отражение человеческого одиночества В мире, [в:] Samotność - aspekty, konteksty, wymiary, t. II, red. K. Arciszewska, L. Kalita, U. Potocka-Sigłowy, Gdańsk 2016, c. 274-282.

${ }^{3}$ См. М. В о л ь ф, Софистика. Горгий Леонтийский: Трактат "О не-сущем, или О природе" в современных интерпретацииях, Новосибирск 2014.

${ }^{4}$ Cм. W. T a t a r k i e w i c z, Historia filozofii, t. I: Historia starożytna i średniowieczna, Warszawa 2009, c. 41; A. K e n n y, Ancient Philosophy, New York 2004, c. 31.

5 Там же, с. 148.

${ }^{6} \mathrm{Cp}$.:

Людям известно, что замыкание нейронных цепочек в коре мозга определенным образом связано с мыслями. Им известна даже локализация переживаний - какие
} 
возможно однозначно установить, насколько вышеприведенный ход размышлений отражает искреннее миросозерцание Горгия, так как он может оказаться лишь только проявлением чисто умственно развлекательной языковой игры, к которой безусловно клонил философ из Леонтин ${ }^{7}$. Однако следует отметить, что, независимо от их мотивировки, эпистемологические выводы, сделанные в трактате О не-сущем, или О природе, несомненно оставили свой отпечаток на деятельности целого ряда выдающихся европейских мыслителей.

В данном контексте следует указать прежде всего на Рене Декарта, Джорджа Беркли и Дэвида Юма ${ }^{8}$, которые оказали огромное влияние на современное понимание доктрины солипсизма. Первый из вышеупомянутых философов - Картезий - в своих размышлениях о границах научного наблюдения за действительностью познающий субъект определил как res cogitans, мыслящую субстанцию, которая замыкается в индивидуальном сознании ${ }^{9}$. К тому же Рассуждений о методе при методологической проверке положений, связанных с гносеологией и онтологией, пользовался аргументами, характерными для скептицизма: 1) иллюзорностью чувств, 2) отсутствием заметной разницы между сном и явью, и 3) возможностью заблуждения, введенного существом, которое мощнее человека. Однако следует подчеркнуть, что

ощущения соответствуют активности разных зон мозга. Например, возбуждение нейронов в определенной области совпадает с переживанием красного цвета. Пока все просто. „Hard problem” появляется, когда они пытаются объяснить, как электрическая активность, которую фиксируют приборы, становится субъективным чувством. Тем, что люди называют qualia - переживанием чего-то изнутри. Вот как мы знаем, что эта доска черная, а щеки у Рамы красные... [...]

- Объяснить это не представляется возможным [...] Как, где и почему электрический разряд становится красным цветом, который мы видим? Этого не знает никто из людей. Иногда даже спорят, можно ли утверждать, что красное для одного человека - то же самое, что красное для другого. С уверенностью можно говорить лишь о том, что в схожих ситуациях люди используют одно и то же слово.

В. П е л е в и н, Бэтман Апомо, Москва 2013, с. 80-81.

7 Интересно, что Пелевина, солипсистское мировосприятие которого полно похожих квазисерьезных рассуждений, некоторые критики упрекают именно в неискренности мировоззренческой позиции и языковом релятивизме. Ср. И. 3 о т о в, Пелевин как капитан Лебядкин, [в:] электронный ресурс: http://www.utro.ru/articles/ 2003/09/17/232710.shtml (19.05.2014).

8 Беркли и Юм упоминаются как Тимуром Тимуровичем в описании болезни Петра Пустоты в романе Чапаеb и Пустота, так и лисой А Хули в Священной книге оборотня. Зато Картезий появляется в размышлениях графа Т. в романе Т. См. В. П е л е в и н, Чапаев и Пустота, Москва 2012, с. 162-163; его же, Священная книга оборотня, Москва 2015, с. 284; его же, Т, Санкт-Петербург 2015, с. 172.

${ }^{9} \mathrm{~W}$. T a t a r k i e w i c z, Historia filozofii, t. II: Historia nowożytna do roku 1830, указ. соч., c. 54 . 
Декарт не поддался сомнениям в реальности бытия, найдя опору существования в мыслящем субъекте. Французский философ выразил это убеждение в своем общеизвестном положении cogito ergo sum, т. е. мыслю, следовательно, существую. Такая постановка вопроса имплицирует следующее: насколько можем сомневаться в реальности окружающего мира, по-картезиански определяемого как res extensa, мыслящее сознание есть, так как осознает само себя ${ }^{10}$. Итак, дуализм Декарта, т. е. разделение объектов, находящихся в мире, на материю и духа, соответственно протяженную и мыслящую субстанцию, совмещает элементы скептицизма, а может быть, даже крайнего солипсизма, и онтологической метафизики, согласно которой сознание несомненно существует в полной независимости от тела. Картезианский переворот в философии оказал огромное воздействие на дальнейшее развитие европейской мысли вплоть до современности.

Еще в XVII веке, но уже после смерти Картезия, понятие „солипсизм" стало предметом горячих философских споров в связи с деятельностью ирландского мыслителя Джорджа Беркли, поставившего его в центр своей мировоззренческой системы. Автор Трактата о принциnах человеческого знания не только продолжил традиции картезианского дуализма и эмпиризма Джона Лока, но и создал их радикальные формы. Беркли утверждал, что все объекты человеческого познания воспринимаются как идеи, основанные на трех базовых источниках - человеческих чувствах, памяти и воображении, а также на умственной переработке знаний, полученных с помощью чувств или воображения ${ }^{11}$. К тому же ирландский философ с полной уверенностью заметил, что реальность может существовать только по принципу esse est percipi, т. е. существовать - значит быть воспринятым ${ }^{12}$.

В таком ракурсе существовать может только то, что осознается умом $^{13}$. Итак, мир, по Беркли, состоит из воспринимаемых (percipi) идей и воспринимающих (percipere) их духов. Следовательно, идеи зыбки и зависимы от ума. Критики такой постановки вопроса указывали на устойчивость и единство перцепции предметов на протяжении времени, которые мыслитель, в свою очередь, объяснял божественной

10 Там же.

${ }_{11}$ См. Дж. Б е р к л и, Трактат о приниииах человеческого знания, [в:] его же, Сочинения, пер. с анг., Москва 1978, с. 171.

12 Там же, с. 172.

13 Джон Лок утверждал, что границы нашего опыта являются границами нашего знания. Беркли это положение приводит к радикальной форме - границы нашего опыта являются границами бытия. Cp. W. T a t a r k i e w i c z, Historia filozofii, указ. соч., t. II, с. 120. 
природой восприятия, полагая, что человеческое познание всегда сопровождается Божьим взором ${ }^{14}$.

Критикой картезианского дуализма и продолжением берклианского имматериализма в XVIII веке можно считать философские рассуждения Дэвида Юма. В отличие от Картезия и Беркли, шотландский эмпирист не только отказался признать существование физической материи, но также утверждал, что сознающее "я" в такой же степени является иллюзией ${ }^{15}$. Юм пришел к выводу, что самость невозможно познать, так как ее восприятие ограничено всего лишь некоим комплексом впечатлений, лишенным постоянной природы и протяженности ${ }^{16}$. Необходимо заметить, что автор Трактата о человеческой природе в своем скептицизме ограничивался эпистемологическими положениями, исключая возможность познания, основанного на фактических отношениях между объектами впечатлений и идей.

Вышеприведенные достижения философской мысли складываются на сегодняшнюю форму доктрины солипсизма, которая сыграла огромную роль в рамках постмодерна, как в области философии, так и в художественных текстах второй половины XX и начала XXI веков. Сoлипсическая мировоззренческая позиция предполагает максимально привилегированный статус "я" в гносеологическом и онтологическом планах ${ }^{17}$. Следовательно, субъект не является частью мира, а всем миром, не оставляя в нем места для других проявлений бытия ${ }^{18}$. В таком ракурсе главным положением солипсизма оказывается нескромно звучащее „мир является моим [курсив - М. Я.] миром"19, равнозначное констатации „существую только я" 20. Итак, „я" не только выполняет всю доступную познанию действительность, но и создает ее по берклианскому закону esse est percipi. Такой способ восприятия действительности, однако, ведет к неминуемому тупику, который можно выразить в форме простого вопроса: „если мир создается-воспринимается еди-

14 Там же, с. 122. Ср. В. Пе л е в и н, Священная книга оборотня, указ. соч., с. 283-284.

15 CM. A. Ke n n y, Philosophy in the Modern World, New York 2007, c. 164.

16 W. T a t a r k i e w i c z, Historia filozofii, указ. соч., t. II, с. 129-130.

17 D. P h i 11 i p s, Logic, Reality, and God, [в:] The Oxford Handbook of Philosophy of Religion, edited by W. Wainright, New York 2005, c. 457.

18 Cм. G. H a g b e r g, Describing Ourselves. Wittgenstein and Autobiographical Consciousness, New York 2008, с. 17-18.

${ }^{19}$ Цитата приводится в нашем переводе по изданию: D. P e a r s, The False Prison: A Study of the Development of Wittgenstein's Philosophy, vol. 1, Oxford 1987, c. 160. CM. также: М. J a w o r s k i, Solipsyzm jako perspektywa poznawcza w twórczości Wiktora Pielewina, [в:] Literatura u progu XXI wieku, pod red. J. Chłosty-Zielonki i Z. Chojnowskiego, Olsztyn 2014, c. 403-411.

${ }^{20}$ Cp. R. S o r e n s e n, A Brief History of the Paradox, New York 2003, c. 172. 
ноличным сознанием, то где тогда находится оно само?". Именно эта своеобразная лакуна солипсизма, как нам кажется, существенно сближает его с постмодернистской поэтикой, основанной на интересе к онтологическим вопросам ${ }^{21}$, так как обыгрывание безвыходного характера солипсистского восприятия-создания намекает на возможность сосуществования многих миров.

Очерк трактовки солипсизма в философском дискурсе, на наш взгляд, весьма полезен при деконструкции пелевинского подхода к этой идее, понимаемой как предмет реконфигурации. Автор Чапаева и Пустоты неоднократно намекает на традицию солипсистского понимания действительности, одновременно создавая его новый оригинальный образ. На основе внимательного прочтения интересующих нас художественных произведений можно однозначно констатировать, что этот диалог не только обнаруживается во всех романах Пелевина, но также придает реконфигурируемой доктрине солипсизма своеобразный и неповторимый характер. В дальнейших рассуждениях попытаемся проанализировать основные элементы пелевинского солипсизма, пронизывающие глубинную структуру романной поэтики творчества автора Желтой стрелы.

Главной опорой солипсистского мироощущения в данном контексте мы считаем полную неразделимость познающего субъекта и окружающей его действительности. Это означает, что в рамках идейного содержания романов Пелевина отсутствует (полностью или частично) подразделение элементов реальности на субъекты и объекты. В так понимаемой действительности нельзя начертить границу между единоличным сознанием и окружающим его внешним миром. Эта имманентная онтологическая размытость в письме Пелевина сопровождается, или, может быть, даже вызвана, демиургическим характером функционирования человеческого ума. Внешняя и внутренняя реальности тождественны, так как воспринимающее сознание создает объект своей собственной направленности. Например, в Жизни насекомых в результате формальной реконфигурации такая трактовка данного вопроса приобретает вид секретных знаний, доступ к которым субъект получает во время ритуала инициации. К тому же этим субъектом в тексте Пелевина оказывается молодой жук-навозник, допущенный к секрету восприятия действительности своим отцом. Целью поучения в данном произведении Пелевина является своеобразное пробуждение, эпифанический опыт наподобие прозрения:

- Я знаю, это сложно понять, - сказал он [навозник-отец - М. Я.]. Но кроме навоза, ничего просто нет. Все, что я вижу вокруг, - отец широким же-

${ }^{21}$ См. В. M c H a l e, Powieść postmodernistyczna, tłum. M. Płaza, Kraków 2012, c. 13. 
стом обвел туман, - это на самом деле Йа. И цель жизни - толкать ее вперед. Понимаешь? Когда смотришь по сторонам, просто видишь Йа изнутри. $[\ldots]-$ И все вокруг и есть этот шар?

Отец опять кивнул 22.

Это аллегорическое представление интересным образом намекает на ограниченность человеческого восприятия и его сугубо индивидуальный характер. Ведь если „я" („Йа") одновременно принадлежит индивиду и заполняет весь окружающий его мир, тогда сосуществование, со-бытие, многих индивидов указывает на возможность существования множества миров, замыкающихся в индивидуальном сознании субъектов ${ }^{23}$.

При логическом разборе такого положения, неслучайно схожего с берклианским esse est percipi, мы неизбежно столкнемся с присущим солипсистской позиции тупиком, связанным с отсутствием местонахождения проецирующего реальность сознания ${ }^{24}$. Эта проблема играет немаловажную роль в третьем романе Пелевина - Чanaeb и Пустоma (1996). Здесь мы имеем в виду не только известный разговор Петра с Чапаевым о природе восприятия ${ }^{25}$, но прежде всего размышления

22 В. П е л е в и н, Жизнь насекомых, Москва 2015, с. 33-34.

23 Такое положение стоит сравнить со словами Александра Гениса:

Окружающий мир для Пелевина - это череда искусственных конструкций, где мы обречены вечно блуждать в напрасных поисках „сырой”, изначальной действительности. Все эти миры не являются истинными, но и ложными их назвать нельзя, во всяком случае до тех пор, пока кто-нибудь в них верит. Ведь каждая версия мира существует лишь в нашей душе, а психическая реальность не знает лжи.

А. Г е н и с, Поле чудес, [в:] электронный ресурс: http://pelevin.nov.ru/statio-gen 2/1.html (09.09.2016).

24 Хотя следует также отметить возможное влияние философии буддизма, в особенности идеи действительности, являющейся сном демиурга Брахмы. См. А. А ф ан а с ь е в а, Сновидения В постмодернизме как отдельная реальность, „Вестник КазНУ. Сер.: Филологическая" 2014, № 2 (148), с. 176-181.

25 - [...] Скажи-ка мне, где эта манда живет?

- В моем сознании?

- А сознание твое где?

- Вот здесь, - сказал я, постучав себе по голове.

- А голова твоя где?

- На плечах.

- А плечи где?

- В комнате?

- А где комната?

- В доме.

- А дом?

- В России.

- А Россия где?

[...] - Ну как где. На Земле.

- А Земля где? 
Пустоты после разговора с Котовским, своего рода духовным двойником Чапаева, которые не только являются очередной реконфигурацией данного элемента пелевинского солипсизма ${ }^{26}$, но также становятся отправной точкой для последующего развития сюжета:

Если весь мир существует во мне, то где тогда существую я? [...] Можно было бы сказать, думал я, что мир, с одной стороны, существует во мне, а, с другой стороны, я существую в этом мире, и это просто полюса одного смыслового магнита, но фокус был в том, что этот магнит, эту диалектическую диаду негде было повесить.

Ей негде было существовать.

Потому что для ее существования нужен был тот, в чьем сознании она могла бы возникнуть 27.

Данный вопрос Пелевин решает со свойственной себе легкостью - мироздание и, соответственно, человеческий ум обладают многоуровневой структурой, в рамках которой отдельные сознания создают микромиры, на самом деле являющиеся лишь только мыслями Абсолюта, т. е. некоего Гиперсознания, занимающего бесконечность бытия целиком. С перспективы нынешнего анализа весьма интересным вариантом изображения Абсолюта, на наш взгляд, является его вампирическое воплощение, предложенное Пелевиным в романе Бэтман Аполло. Великий Вампир, по определению целого ряда учителей-наставников Рамы, оказывается суммой всякой возможности возникновения бытия. Озирис - герой, уже прошедший значительную часть пути к просвещению, в своем учении объясняет своему неопытному коллеге-ныряльщику настоящую природу реальности следующим образом:

Мы просто слуги Великого Вампира, который проделывает с нами то же самое, что с людьми. [...] Даже голова у тебя на плечах не твоя. Все это личная собственность Великого Вампира. И то, что представляется тебе внешней реальностью, и то, что прикидывается твоим внутренним миром, тобою самим [...]. Это не твое. Все это тебе ни к чему. [...] Великий Вампир нужен только себе самому. Во вселенной есть лишь он и его невидимые зеркала, которые и есть мир 28 .

- Во Вселенной.

- А Вселенная где?

[...] - В моем сознании.

- Так что же, Петька, выходит, твое сознание - в твоем сознании?

В. П е л е в и н, Чапаев и Пустота, Москва 2012, с. 216.

${ }_{26}$ См. В. П е л е в и н, T, указ. соч., с. 362-365; его же, S.N.U.F.F., Москва 2015, с. 432; его же, Бэтман Апомло, Москва 2013, с. 150; его же, Смотритель. Орден желтого флага, Москва 2015, с. 25.

27 Там же, с. 228-229.

28 В. П е л е в и н, Бэтман Аполл, Москва 2013, с. 360-361. 
Любопытно, что вышеприведенные слова не исключают узловой роли (человеческого по своей природе) сознания в выработке действительности, а только дополняют доминирующую в данном романе солипсистскую мировоззренческую позицию. Озирис опровергает противоположность Божьего всемогущества и крайнего человеческого индивидуализма, неслучайно пользуясь аргументом, напоминающим вышеуказанные толкования Джорджа Беркли - человеческое „я" создает (и целиком выполняет) весь мир, но само принадлежит некоему Сверхсознанию, находясь в поле присущего ему Сверхвосприятия ${ }^{29}$.

Интересно, что анализ романов Пелевина может привести внимательного читателя к признанию враждебного характера такой обстановки дел. Именно поэтому многие персонажи интересующих нас произведений автора Смотрителя единственный путь к спасению усматривают в остановке мысленного процесса, создающего мир, полный страдания. Прекращение генерирования действительности в свете ее однозначно неприязненной природы оказывается не только восстанием против Божьей тирании, но также уходом от боли и печали, наполняющих человеческую жизнь. Поощрение к попытке прекратить думать-создавать мир, по сути дела ведущее к эпифаническому опыту, оказывается одним из важнейших реконфигурируемых лейтмотивов в пелевинском письме. Автор Смотрителя в целом ряде своих произведений изображает идею низвержения абсолютной власти вышеупомянутого Гиперсознания, причем способы реализации данного задания отличаются высокой степенью художественной изощренности ${ }^{30}$. На наш взгляд, интересным примером такой реализации является концепт „Оптина Пустынь”, предложенный русским писателем в Т. Главный герой данного текста - граф Т. - проходит символический путь, полный испытаний, чтобы наконец узнать настоящее значение своих странствий:

Слово „Оптина” происходит от латинского глагола „oparte” - „выбирать, желать". Здесь важны коннотации, указывающие на бесконечный ряд возможностей. Ну а „Пустынь" - это пустота, куда же без нее ${ }^{31}$.

29 Ср. В. П е л е в и н, Любовъ к трем иукербринам, Москва 2014, с. 43-44.

30 Из-за очевидных формальных причин мы вынуждены ограничиться только одним примером, но стоит упомянуть и другие релевантные реконфигурационные варианты, например: хум (Generation „П"), Радужный Поток (Чапаеb и Пустота, Священная книга оборотня), Черный Путь (Бэтман Аполо), Сжигатели Пленки (S.N.U.F.F.). См. В. П е л е в и н, Generation „П", Москва 2014, с. 71; В. П е л е в и н, Чапаев и Пустота, указ. соч., с. 472-473; В. П е л е в и н, Священная книга оборотня, указ. соч., с. 375-380; В. П е л е в и н, Бэтман Аполо, указ. соч., с. 272-273; В. П е л е в и н, S.N.U.F.F., указ. соч., с. 390-391.

31 В. П е л е в и н, Т, указ. соч., с. 408-409. 
Следовательно, Оптина Пустынь, вопреки ожиданиям Т., является не пространственной точкой на его пути, а духовным состоянием, полностью лишенным как материальной основы, так и категории индивидуального бытия.

Солипсическую картину мира в творчестве Пелевина (на уровне реконфигурируемой идеи) дополняет мотив несовершенства восприятия посредством человеческих органов чувств, роль которых в таком ракурсе опирается на внушение ложного образа действительности. Автор Священной книги оборотня акцентирует прежде всего вторичный характер перцепции, предполагая, что она всегда подвергается предварительной умственной переработке, придающей ей неизбежно ложный характер. К тому же из-за лукавости ума этой имманентной неискренности восприятия сопутствует впечатление априорности перцепции по отношению к осознанию, что усиливает эффект миража. В Empire „ $V$ " можем прочитать:

мы живем не среди предметов, а среди ощущений, поставляемых нашими органами чувств. То, что мы принимаем за звезды, заборы и лопухи, есть просто набор нервных стимулов. Мы наглухо заперты в теле, а то, что кажется нам реальностью - просто интерпретация электрических сигналов, приходящих в мозг. Мы получаем фотографии внешнего мира от органов чувств. А сами сидим внутри полого шара, стены которого оклеены фотографиями. Этот полый шар и есть наш мир, из которого мы никуда не можем выйти при всем желании. Все фотографии вместе образуют картину мира, который, как мы верим, находится снаружи ${ }^{32}$.

Этот элемент пелевинской трактовки солипсизма характеризуется широкой гаммой оттенков и интенсивности, так как несовершенство восприятия с помощью чувств в романах Пелевина необязательно охватывает всю реальность, оставляя пространство для смешивания придуманного с настоящим, виртуального с истинным, а может быть, даже сочетания нереального с еще более нереальным, ведущего к одобрению идеи сосуществования множества параллельных, но, вопреки законам математики, пересекающихся измерений ${ }^{33}$.

Кроме того, действительность, функционирующая по законам крайнего индивидуализма, ведь слово „солипсизм” происходит от латинских solus и ipse, означающих соответственно „один, единственный” и „сам"34, в прозе Пелевина является причиной безграничного оди-

32 В. П е л е в и н, Empire "V": повесть о настоящем сверхчеловеке, Москва 2015, c. $170-171$.

33 Ср. В. П е л е в и н, Generation „П”, указ. соч., с. 77-78.

${ }_{34}$ С. Н е к р а с о в, Н. Н е к р а с о в а, Философия: тематический словарь, ч. 1: История философии, Москва 2008, с. 35. 
ночества человека, его замкнутости по отношению к другому. В мире, создаваемом по принципу солипсизма, не существует истинного диалога между двумя полноправными субъектами ${ }^{35}$. Следовательно, романы автора Любви к трем цукербринам полны монологической речи, притворяющейся диалогом, так как их герои создают очередной мираж - ложное со-бытие ${ }^{36}$. Жизнь в окончательной пустоте собственного сознания настолько невыносима, что человек, как предполагает Пелевин, по своей природе вынужден участвовать в беспрерывном производстве мнимых спутников, облегчающих бытие. Здесь стоит привести пример главного героя романа Смотритель - Алекса, который, разочаровавшись в привилегиях жизни молодого аристократа, ищет настоящую любовь и находит ее в виде искусного самовнушения, т. е. миража женщины, созданного в результате созидательной работы ума, - „зеленки” Юки. Новая спутнища Алекса, помимо своей очевидной нереальности, оказывается, как многократно подчеркивается в повествовании, несравнимо лучше настоящей женщины ${ }^{37}$.

Целью настоящей статьи было представление предварительных результатов анализа солипсистской позиции в пределах романного творчества Виктора Пелевина в ключе поэтики реконфигурации, опирающейся на гипотезу о различии сугубо идейного и формального пластов пелевинского письма ${ }^{38}$. Итак, на основе вышеприведенных размышлений можем констатировать, что реконфигурируемая идея солипсизма в интересующих нас текстах автора Священной книги оборотня опирается на специфическую трактовку вопросов, связанных с имманентной неразличимостью внешней и внутренней реальностей, созидательной работой ума, вездесущим Гиперсознанием и стремлением к уничтожению миража действительности. Следует заметить, что данная проблема, на наш взгляд, представляет собой многообещающий предмет дальнейших исследований.

35 Ср. М. Я в о р с к и, указ. соч., с. 274-282.

36 Здесь со-бытие понимается как соприсутствие, т. е. как модус бытия среди других субъектов. Ср. М. Х а й д е г г е р, Бытие и время, пер. В. Бибихина, Харьков 2003, с. 141-150; История философии: энииклопедия, под ред. А. Грицанова, Минск 2002, c. 934-938.

37 См. В. П е л е в и н, Смотритель. Орден желтого фляага, Москва 2015, с. 82-85. В данном контексте несомненно следует упомянуть также о спутнице главного героя романа S.N.U.F.F. - суре Каи. См., напр.: В. П е л е в и н, S.N.U.F.F., указ. соч., c. $58-67$.

38 Анализ романного творчества в ключе реконфигурации является предметом еще не законченной нами диссертационной работы под названием Реконфигурация в романной поэтике Виктора Пелевина. Солипсизм - язык - история. 


\section{Библиография}

А ф а н а с ь е в а А., Сновидения $b$ постмодернизме как отдельная реальность, „Вестник КазНУ. Сер.: Филологическая" 2014, № 2 (148), с. 176-181.

Б е р к л и Дж., Трактат о принципах человеческого знания, [в:] его же, Сочинения, пер. с анг., Москва 1978.

В о л ь ф М., Софистика. Горгий Леонтийский: Трактат „О не-сущем, или О природе” в современных интерпретациях, Новосибирск 2014.

Г е н и с А., Поле чудес, [в:] электронный ресурс: http://pelevin.nov.ru/stati/o-gen 2/1.html (09.09.2016).

З о т о в И., Пелевин как капитан Лебядкин, [в:] электронный ресурс: http://www.utro. ru/articles/2003/09 /17/232710.shtml (19.05.2014).

История философии: энииклопедия, под ред. А. Грицанова, Минск 2002.

Н е к р ас о в С., Н е к р а с о в а Н., Философия: тематический словарь, ч. 1: История философии, Москва 2008.

Н е м з е р А., Как я упустил карьеру, [в:] электронный ресурс: http://pelevin.nov. $\mathrm{ru} / \mathrm{stati} / \mathrm{o}-\mathrm{nemz} / 1 . \mathrm{html}(05.04 .2016)$.

С в е р д л о в М., Хорошая защита плохой прозы, [в:] электронный ресурс: http://www.globalrus.ru/impressions/133635 (01.12.2015).

Я в о р с к и М., Нарративныйринцип солипсизма $b$ mворчестве В. Пелевина как отражение человеческого одиночества в мире, [в:] Samotność - aspekty, konteksty, wymiary, t. II, red. K. Arciszewska, L. Kalita, U. Potocka-Sigłowy, Gdańsk 2016, c. 274-282.

П е л е в и н В., Бэтман Аполло, Москва 2013.

П е ле в и н В., Жизнь насекомых, Москва 2015.

П е л е в ин В., Любовь к трем цукербринам, Москва 2014.

П е л е в и н В., Священная книга оборотня, Москва 2015.

П е ле в и н В., Смотритель. Орден желтого флага, Москва 2015.

П е л е в и н В., Т, Санкт-Петербург 2015.

П е л е в и н В., Чапаев и Пустота, Москва 2012.

Пе л е в и н В., Empire „V": повесть о настоящем сверхчеловеке, Москва 2015.

П е л е в ин В., Generation „П", Москва 2014.

П е л е в ин В., S.N.U.F.F., Москва 2015.

Х а й д е г г е р М., Бытие и время, пер. В. Бибихина, Харьков 2003.

$\mathrm{H}$ a g b e r g G., Describing Ourselves. Wittgenstein and Autobiographical Consciousness, New York 2008.

J a w o r s k i M., Solipsyzm jako perspektywa poznawcza w twórczości Wiktora Pielewina, [в:] Literatura u progu XXI wieku, pod red. J. Chłosty-Zielonki i Z. Chojnowskiego, Olsztyn 2014, c. 403-411.

Ke n n y A., Ancient Philosophy, New York 2004. 
Ke n n y A., Philosophy in the Modern World, New York 2007.

M c H a l e B., Powieść postmodernistyczna, tłum. M. Płaza, Kraków 2012.

P e a r s D., The False Prison: A Study of the Development of Wittgenstein's Philosophy, vol. 1, Oxford 1987, c. 154-192.

P h 111 i p s D., Logic, Reality, and God, [в:] The Oxford Handbook of Philosophy of Religion, edited by W. Wainright, New York 2005.

S o r e n s e n R., A Brief History of the Paradox, New York 2003.

$\mathrm{T}$ a $\mathrm{t}$ a r k i e w i c z W., Historia filozofii, t. I: Historia starożytna i średniowieczna, Warszawa 2009.

T a t a r k i e w i c z W., Historia filozofii, t. II: Historia nowożytna do roku 1830, Warszawa 2009. 
